\title{
Supporting self-care of long-term conditions in dementia: A systematic review
}

\begin{abstract}
Background: Long-term conditions are common in people living with dementia; their selfmanagement is an important determinant of wellbeing. Family carers often support or substitute selfcare activities, and act as proxies for self-management, as dementia progresses.

Objectives: To conduct the first systematic review of how management of long-term conditions in people with dementia is best enabled and supported, including factors that facilitate or inhibit selfmanagement and management by a proxy.
\end{abstract}

Design: Systematic review.

Data Sources: We systematically searched MEDLINE, PsychINFO, Embase and Allied and Complementary Medicine databases up to November 2018.

Review Methods: We identified the long-term conditions most prevalent in people with dementia that require an element of self-management. We then developed our inclusion criteria to identify qualitative and quantitative studies describing the self-management (or self-management assisted by family carers) of long-term conditions in people with dementia. Two authors independently rated study validity using a standardised checklist. We synthesised qualitative and quantitative findings using a data driven convergent synthesis approach.

Results: We included 12 articles meeting predetermined inclusion criteria: seven qualitative, two case studies, two quantitative and one mixed methods study. We identified four main themes across these studies: (1) dementia symptoms impeding treatment regimens (forgetfulness, decreased understanding, ability to communicate symptoms and behavioural and psychological symptoms); (2) adapting routines to be simpler, (using memory aids and accommodating physical limitations); (3) negotiating self-management support (carer availability and knowledge; balancing needs for safety and empowerment); and (4) interface with professionals, who can assist by simplifying routines, providing long-term condition specific education, and acknowledging the carer role in care planning.

Conclusions: Carers can support people living with dementia to continue managing their own health for as long as possible, through simplifying routines and reminding, but where this can no longer be negotiated, carers take over responsibility for self-management, often due to safety concerns. Empowerment of people with dementia to remain involved in their care as far as possible reduces the loss experienced by this transition. Communication and partnership between clinicians and planning for people living with dementia and a long term condition should include explicit discussion of how these partnerships will work and carers is critical when supporting people living with a long-term condition and dementia. Care guidance on strategies carers can use to support people to self-manage long-term conditions.

Keywords: Dementia, Long-term conditions, Management, Multi-morbidity, Physical Health, Review, Self-care. 


\section{Acknowledgments}

This work was supported by the Economic and Social Research Council [grant number ES/P000592/1]; and the National Institute of Health Research (NIHR) Collaboration for Leadership and Applied Health Research (North Thames). The views expressed are those of the author(s) and not necessarily those of the NIHR or the Department of Health and Social Care.

\section{Contribution of the paper}

What is already known about the topic?

- People living with dementia are less likely to receive good quality physical healthcare.

- Dementia symptoms significantly impact on self-management of long-term conditions.

- Previous reviews have primarily studied the impact on people with dementia of living with one long-term condition, despite the rise in multi-morbidity.

What this paper adds?

- Collaboration and communication between stakeholders is crucial.

- Enabling factors include establishing a routine and memory aids, and negotiating support of carers for self-management.

- Barriers to long-term condition management in dementia include communication difficulties and challenges of balancing safety concerns with the wish to avoid deskilling and independence. 


\section{Introduction}

The global prevalence of dementia is increasing. It is predicted that 131.5 million people will be living with the condition by 2050 (Prince et al., 2015). Multiple chronic conditions affect two-thirds of people aged over 85 (Kingston et al., 2018) and over 90\% of people with dementia are reported to have a comorbid chronic condition ( Browne et al., 2017). The most frequent comorbid, long-term conditions include hypertension, diabetes, heart disease, stroke, osteoporosis, thyroid disorders and breathing difficulties such as asthma and chronic obstructive pulmonary disease (COPD; Browne et al., 2017; Poblador-Plou et al., 2014; Schubert et al., 2006).

Present healthcare service structures and clinical guidelines tend to focus on single conditions, and may require significant adaptation to address the needs of the growing population of people living with dementia and long-term conditions (Bunn et al., 2016; Guthrie et al., 2012). Like all older people, people living with dementia who have more chronic conditions experience greater disability, mortality and poor quality of life (Black et al., 2012; Marengoni et al., 2011).

Management of long-term conditions accounts for over two-thirds of health and social care expenditure (Department of Health and Social Care, 2012). Research has indicated that the quality of physical health care received by people with dementia differs from the general population. People with dementia receive fewer physical health checks and primary care contacts than people without dementia (Cooper et al., 2017). Dementia may reduce the ability of an individual to self-manage coexisting long-term conditions, for example through difficulties recalling appointments or treatment regimens (Rosen et al., 2003), judging what treatment is appropriate (Ibrahim et al., 2017), and reduced medication adherence (Brauner, 2009).

Literature reviews relating to long-term conditions in dementia have investigated the impact of cognitive impairment on self-management of chronic diseases, including COPD (Baird et al., 2017), heart failure (Currie et al., 2015) and diabetes (Santos et al., 2018). These reviews explored inhaler techniques, medication for management of heart failure and blood glucose control respectively. They explored the impact of dementia on self-management, but do not suggest strategies to support selfmanagement of long-term conditions in people living with dementia. Existing self-management interventions for people with dementia seek to reduce their dementia-related symptoms such as memory loss, rather than improving self-management of comorbid conditions (Quinn et al., 2016). Similarly, medication management interventions for dementia focus on anti-dementia medication, even though the great majority of medication prescribed to people with dementia is for physical health conditions (Aston et al., 2017; Lim and Sharmeen, 2018). A recent realist review used a theory-driven approach to synthesise the mechanisms by which diabetes can be managed in people with dementia. The review suggested that the identification of family members to help was an integral part of selfmanagement care planning (Bunn et al., 2017b; Wong et al., 2013).

\section{Aim and objectives}

We aimed to synthesise evidence on how the management of long-term conditions in people with dementia can be supported, and to explore what factors may enable or inhibit this support.

Management in this review is define as either self-management, or management supported by a proxy (where people carry out self-management activities for those unable to do so). The term proxy refers to family or friend carers, or staff in care homes or assisted living facilities. We focussed on the longterm conditions that are prevalent in people living with dementia, and which require an element of self-management. 
Figure 1: PRISMA diagram of study selection (adapted from Moher et al., 2009)

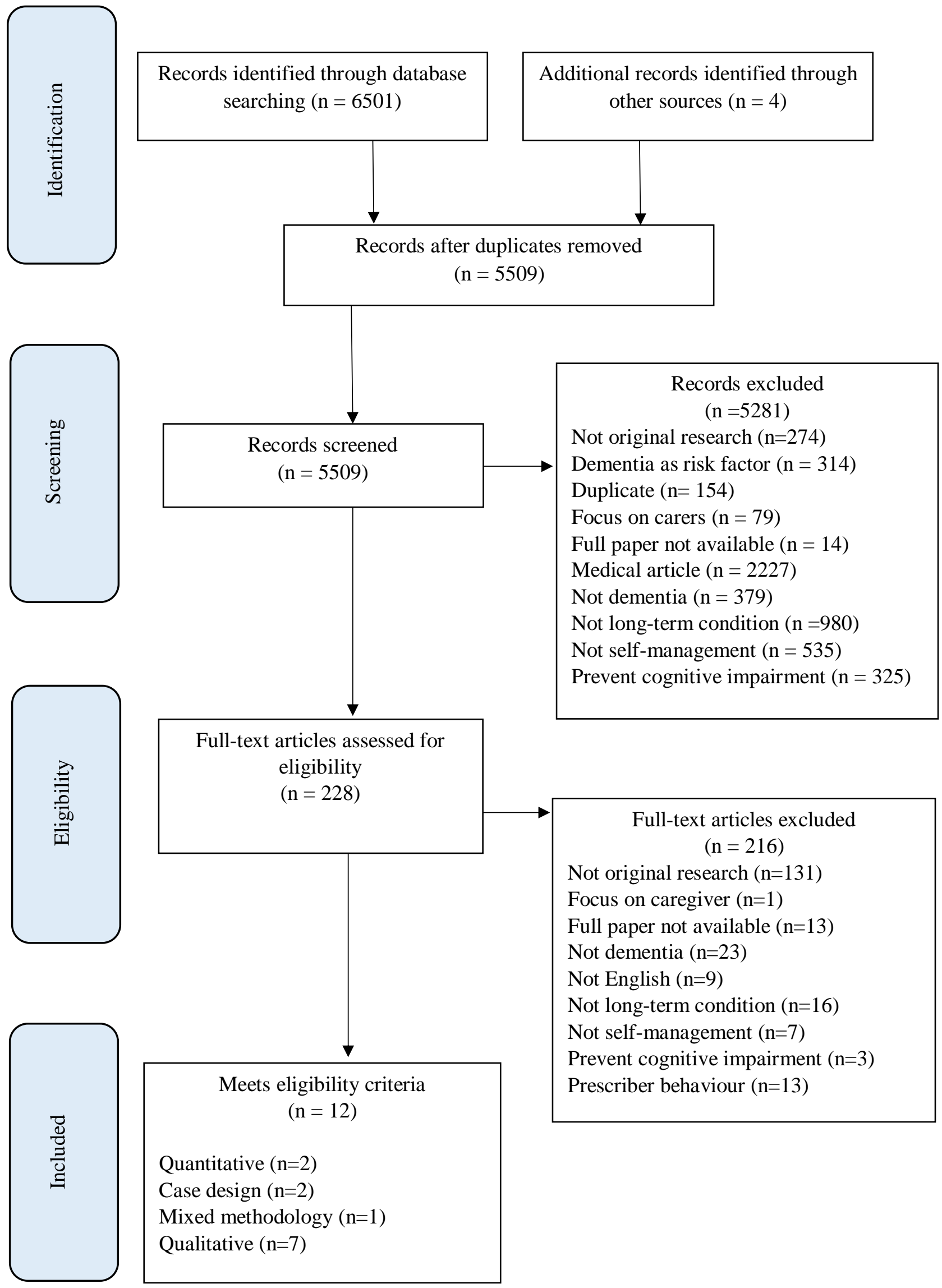




\section{Search strategy}

3 We systematically reviewed the literature up to the $28^{\text {th }}$ November 2018 with no limits applied to date

4 of publication, using the following databases: MEDLINE, PsychINFO, Embase and Allied and

5 Complementary Medicine. We registered the review on PROSPERO (reference number:

6 CRD42019122072). We searched references of identified articles, including systematic reviews, and

7 conducted forward searches for additional relevant studies. Terms related to 'dementia,' 'physical

8 health', and 'management' were combined using the Boolean operator 'AND.' The Boolean operator

9 'OR' linked search terms within each concepts. See Table 1 for the full search strategy.

Study selection

\section{Eligibility criteria}

Studies were eligible for inclusion if they explored an element of self-management, or management by a proxy, of a long-term condition of interest in people living with dementia, in the community or a residential setting. We identified long-term conditions of interest based on prevalence rates reported in a recent, large epidemiological survey of comorbidity in dementia: Hypertension (53.4\%), Chronic Pain (33.5\%), Coronary Heart Disease (21.6\%), Stroke (17.2\%), Diabetes (14\%), Asthma (8.3\%), COPD (6.9\%), Heart Failure (6.3\%; Browne et al., 2017). Studies of long-term conditions in people with dementia were included if they encompassed elements of management including: attending clinical appointments, using medical devices, medication adherence or lifestyle change (Lorig and Holman, 2003). We excluded studies that solely focused on prescriber behaviour; or focused on mental health, as we considered mental health self-management to be conceptually different. No restrictions were applied to study design, including case studies, however reviews, editorials and conference proceedings were excluded. We excluded studies not written in English.

\section{Study screening and data extraction strategy}

Titles and abstracts of references identified in the search were screened in accordance with the inclusion criteria with any uncertainties discussed within the research team. JR and RT assessed a predefined $20 \%$ of papers for which retrieval of full text articles was required, with a moderate rate of inter-rater reliability (Cohen's kappa $=0.50$ ). Two authors $(\mathrm{JR}$ and $\mathrm{RT}$ ) extracted data from papers meeting the inclusion criteria using a standardised data sheet. The wider team assessed and agreed the inclusion of all final studies.

\section{Methodological quality}

We assessed quality of included studies using the Mixed Methods Appraisal Tool (Hong et al., 2018). This was developed to appraise the quality of quantitative, qualitative and mixed methodology studies using a validated checklist to provide a quality rating for each study. Research has demonstrated its efficacy and reliability (Pace et al., 2012). The scale questions are listed in Table 3. Two independent reviewers (JR and RT) assessed the quality of each study using the Mixed Methods Appraisal Tool, with any discrepancies resolved through discussion (required for six full texts).

Analysis

We conducted a narrative synthesis of studies using a data driven convergent synthesis approach (Pluye and Nha Hong, 2014; Popay et al., 2006). This approach has previously been used in mixed methodology reviews (Aston et al., 2017). We first summarised descriptive characteristics. We then used thematic analysis to analyse results sections of included papers, developing codes which were 
combined to create themes and sub themes (Thomas and Harden, 2008). JR and AB independently developed an initial coding framework using line by line coding of the results sections of 4/12 included papers. We then used a constant comparison method to identify similarities and differences and ensure consistency. JR then applied this coding framework to the results sections of all included studies using NVivo software (QSR International Pty, 2018).

\section{Results}

\section{Search results}

We identified 5505 studies in our electronic search, of which eight were included in our review. We identified four additional articles from references of identified papers, so included 12 studies in total. See Figure 1 for details.

\section{Characteristics of included studies (Table 2)}

The included studies were conducted in the United States of America (USA; $n=5$ ), the United Kingdom (UK; $n=3)$ Australia $(n=2)$, China $(n=1)$ and Brazil $(n=1)$. Nine studies used qualitative methodologies, including two case studies. Two studies were quantitative (randomised controlled trial and survey) and one was a mixed methods study. Four studies focused on a single long-term condition, specifically diabetes. The other studies included participants with a range of long-term conditions, including osteoporosis $(n=3)$, hypertension $(n=2)$, stroke $(n=2)$, arthritis $(n=1)$, COPD $(\mathrm{n}=1)$ and heart failure $(\mathrm{n}=1)$. All qualitative studies interviewed family carers $(\mathrm{n}=8)$, studies included family carers only $(n=3)$, family carers and people with dementia $(n=1)$, family carers and healthcare professionals $(n=2)$, or all three stakeholders $(n=2)$. The remaining studies were case studies $(n=2)$ or quantitative $(n=2)$. Six studies reported residential status of the people with dementia who lived in the community $(n=4)$, assisted living facilities $(n=1)$ or care homes $(n=1)$. The remaining studies $(n=6)$ did not report residential status.

\section{Methodological quality}

Five out of nine qualitative studies scored five out of five on the Mixed Methods Appraisal Tool(Bunn et al., 2017a; Feil et al., 2011; Gillespie et al., 2015; Poland et al., 2014; While et al., 2013). Reasons for scoring four out of five were not providing sufficient interpretation of qualitative results (Sadak et al., 2017). For studies that were rated three out of five reasons included lack of information about blinding or adherence to the intervention (Chen et al., 2017), lack of information on data source, collection and analysis (Brauner et al., 2000), incoherence between data collection, analysis and interpretation (Sadak et al., 2018) or due to inappropriate statistical analysis (De Oliveira et al., 2014). One case study scored two out of five for appropriateness of methodology for the research question (Allen et al., 2017). The mixed methodology studies scored one out of five for lack of information (Yarnall et al., 2012). See Table 3 for quality assessment ratings.

\section{Synthesis}

We identified the following themes that play an important role in enabling, supporting or inhibiting the self-management of long-term conditions in dementia. Dementia symptoms inhibited selfmanagement of long-term conditions (theme 1), while adaptations to routines enabled selfmanagement (theme 2). Family carers enabled self-management by proxy when strategies described in theme 2 to support self-management were no longer effective (theme 3 ). Healthcare professionals were integral to supporting both people with dementia and family carers to manage long-term conditions (theme 4). 
See Figure 2 for a list of themes and corresponding sub-themes.

Figure 2: Summary of themes and corresponding sub themes identified from included studies

\begin{tabular}{|c|c|}
\hline Theme 1: Dementia Symptoms & Theme 2: Adapting Routines \\
\hline $\begin{array}{l}\text { Enablers: } \\
\quad \begin{array}{l}\text { Long-term condition pre-existing } \\
\text { dementia }\end{array}\end{array}$ & $\begin{array}{l}\text { Enablers: } \\
\text { • } \quad \text { Establishing routine } \\
\text { • } \quad \text { Memory aids }\end{array}$ \\
\hline $\begin{array}{l}\text { Inhibiters: } \\
\qquad \quad \text { Understanding disease } \\
\text { - } \quad \text { Behavioural and psychological } \\
\quad \text { symptoms (acceptance of care) } \\
\text { - } \quad \text { Communication (of symptoms) }\end{array}$ & $\begin{array}{l}\text { Inhibiters: } \\
\text { - } \quad \text { Physical ability } \\
\text { - } \quad \text { Complex regime }\end{array}$ \\
\hline Theme 3: Negotiating Support & Theme 4: Interface with Professionals \\
\hline $\begin{array}{l}\text { Enablers: } \\
\begin{array}{l}\text { - Availability of carer (supervision) } \\
\text { - Wider support networks } \\
\text { - Empowerment } \\
\text { - Acknowledge carer role }\end{array}\end{array}$ & $\begin{array}{l}\text { Enablers: } \\
\text { - } \quad \text { Recognise change } \\
\text { - Personalised treatment plans (Explore } \\
\text { values/beliefs) } \\
\text { - Continuity of care }\end{array}$ \\
\hline $\begin{array}{l}\text { Inhibiters: } \\
\qquad \text { - Loss of independence } \\
\text { - Safety concerns } \\
\text { - } \quad \text { Deskilling } \\
\text { - } \quad \text { Negative attitudes towards support }\end{array}$ & $\begin{array}{l}\text { - Long-term condition specific education } \\
\text { Inhibiters: } \\
\text { - Reliance on healthcare professionals } \\
\text { - Communication between professionals }\end{array}$ \\
\hline
\end{tabular}

\section{Dementia symptoms impeding treatment regimes}

Cognitive symptoms impeded adherence to dietary and physical activity regimes recommended for self-management of long-term condition, and medication adherence. In a questionnaire study of 217 carers of people with Alzheimer's disease and diabetes or hypertension, higher dementia severity was associated with reduced adherence to lifestyle advice regarding activity, diet and medication regimes. No individuals with severe impairment practiced physical activity regularly, whereas people in the earlier stages of dementia used exercise as a treatment for diabetes or hypertension (De Oliveira et al., 2014).

Qualitative studies explored how cognitive symptoms were sometimes a barrier to self-management or management by a proxy. Often this was because they impaired a person's understanding of the disease and related treatments.

'I give him insulin, I give him his medicine. He takes it, but he questions me, what is this for, why do I have to take so many medicines for. He doesn't remember he's diabetic' (Feil et al., 2011; Family Carer).

Communication difficulties often impaired a person with dementia's ability to report symptoms to family carers or healthcare professionals, and this could inhibit long-term condition management. Family carers reported guessing what symptoms the care recipients were experiencing due to their inability to report symptoms. 
'...I want to do the right thing by him, but he has not been able to tell me when he is ill or hurting for over a year now' (Sadak et al., 2017; Family Carer).

Behavioural and psychological symptoms increased the likelihood of a person refusing assistance to manage their long-term condition. This was described in two qualitative studies that interviewed family carers of people with dementia. Persecutory beliefs could reduce adherence, as one study on medication adherence found people with dementia to have 'altered perceptions about the purpose of the medication(s).' This led to reduced adherence due to the belief that medications were poisonous (Gillespie et al., 2015).

Family carers reported finding refusal of care and persecutory beliefs difficult to cope with in the management of diabetes in dementia.

'He's really angry at me-he tells me I'm the cause of his eye sight being what it is because of the medications I made him take' (Feil et al., 2011; Family Carer).

Lack of acceptance of care by the person with dementia hindered family carer management of longterm condition.

'So I got a big problem... because he's got osteoporosis, he's got a big lung problems. But he doesn't want to take it. I can't do anything' (Gillespie et al., 2015; Family Carer).

Interviews exploring the challenges to diabetes care in people with dementia reported how family carers sometimes misinterpreted refusal of care or behavioural and psychological symptoms as a difficulty in their personal relationship rather than a symptom of dementia, which caused distress (Feil et al., 2011).

The presence of a long-term condition before dementia development was often associated with fewer difficulties with self-management of that condition following a dementia diagnosis. This was described in a qualitative study of the experiences of people with dementia from Australian minority ethnic groups, who successfully managed medication for long-term conditions when they had already been taking the medication prior to developing memory problems.

'My husband he remembers, he takes his own medication what he like [sic] but he only takes the blood pressure tablets because the other tablets he thinks do not do anything to him so it's no worth to take it' (Gillespie et al., 2015; Family Carer).Future care plans may usefully consider how potential barriers to self-management (including poor memory, communication abilities, behavioural symptoms and acceptance) may be impacting an individual. They should also consider the point at which a longterm condition developed and be open to the possibility that effective self-management may be possible even with more advanced dementia, where skills were learnt prior to the dementia developing.

\section{Adapting routines and strategies}

In qualitative interviews, people with dementia who self-administer medication at home, and family carers who support them, a barrier to adherence was regime complexity, specifically confusion around differing daily schedules and varying brand names (While et al., 2013). Simplifying medication regimes enabled self-management. Family carers reported valuing medication reviews in which healthcare professionals reduced the number of daily medications for carers to manage (Gillespie et al., 2015).

Memory aids (such as blister packs or dosette boxes) could enable self-management of medication in milder dementia. 
'... the medication ... he wasn't taking it properly. But now he is taking it regularly ... the Chemist they just fix up the blister pack ... it seems to be excellent' (Gillespie et al., 2015; Family Carer).

The physical limitations of people with dementia also reduced adherence to long-term condition medication. The findings of a qualitative study using a mixture of focus groups $(n=3)$ and semistructured interviews $(n=7)$ with carers of people with dementia demonstrated how long-term conditions such as arthritis affected ability to adhere to medication regimes.

'I think she's starting to have arthritis as well, and she couldn't open the bottles...so she put them in vitamin jars... and I didn't know what was what' (Gillespie et al., 2015; Family Carer).

Establishing a routine enabled self-management of medication, together with memory aids (While et al., 2013). In a case study, the use of technologies supported diabetes insulin self-management in a person with dementia demonstrating how adapting routines is broader than only oral medication (Allen et al., 2017).

\section{Negotiating self-management support}

Included studies described a process towards self-management assisted by a proxy, with transition of responsibility for the management of long-term conditions from people with dementia, either partly or totally, to family carers, where they were available. People with dementia and their carers began to negotiate support for self-management when strategies such as memory aids ceased to be effective, or at a critical point in memory decline, (Bunn et al., 2017a).

Carers supported self-management through managing self-care activities for long-term conditions and monitoring for complications through supervision. A case study of a person living with dementia and diabetes demonstrated a continued ability to appropriately self-manage hypoglycaemia through supervision by staff in assisted living facilities (Allen et al., 2017). One study, exploring the impact of dementia on provision of services for long-term conditions, discussed the vulnerabilities of people with dementia when support for self-management was not available.

'The greatest difficulty is when that individual lives alone and doesn't have an able partner, because then their care can come very disjointed or they're not, they're not able, often they, an appointment's made or they, and they won't answer the door or they forget and so it's when somebody's on their own that you have the biggest issues and lack of joined up care' (Bunn et al., 2017a; Healthcare Professional).

Negotiating support for self-management through proxy-management was a dilemma, in which carers struggled to balance the desire to support independence with that of ensuring good physical health care. A Patient and Public Involvement group exploring medication management in dementia described the impact of accepting help for self-management, in terms of loss of independence.

'I think she felt a loss of independence when the dementia hit. But not only that but as soon as her control over her own medication, that she was so used to, was taken out of her hands' (Poland et al., 2014, Family Carer).

The family carers interviewed considered empowerment as a part of their caregiving role and sought ways to support people with dementia to retain control (Poland et al., 2014). However, a mixed methodology study auditing diabetes care in UK care homes found little evidence of empowerment, with people with dementia dependent on staff for disease management, including foot care and 
diabetes management; only one of eight residents on insulin treatment self-injected or self-monitored blood glucose (Yarnall et al., 2012).

Some studies noted that a desire to deliver good quality physical care could risk deskilling the person with dementia due to high levels of supervision.

'I'm going to oversee all your food now...' (Feil et al., 2011; Family Carer).

A case study of a person with dementia and osteoporosis highlighted the complex risk benefit assessment in treating non-dementia illnesses (Brauner et al., 2000). Family carers found it difficult to balance the risk of non-adherence to treatment with the benefit of independence through selfmanagement.

'Its length of life versus quality of life and that we are carers we're very loathe to face' (Poland et al., 2014; Family Carer).

The knowledge of family carers of cerebrovascular risk factors such as diabetes and hypertension enabled medication and dietary therapy adherence in one study (De Oliveira et al., 2014). 69\% of carers reported an awareness of the need to control hypertension and/or hypercholesterolemia due to the influence of these factors on dementia. This awareness was found to influence adherence to dietary therapy and pharmacological treatment.

Negotiating wider support enabled management by a proxy. Included studies found support groups provided medication information for family carers whose first language was not English (Gillespie et al., 2015). Accessing support from paid carers was found to be hindered by negative beliefs, such as the fear of strangers being incompetent in managing the needs of their relative (Feil et al., 2011). Family carers also reported an ambivalence to involve additional family members suggesting the need for advice on how to access wider support (Feil et al., 2011).

An important element of enabling self-management support was acknowledgement of the family carer role in the management of long-term conditions. This was expressed mainly in terms of healthcare professional acknowledgement but also from extended family (Feil et al., 2011). One study suggested this acknowledgement as a potential intervention target for primary care to prevent healthcare crises.

'Celebrate with caregivers. Offer encouragement and advise to continue keeping symptom monitoring checklists and communicating concerns if they arise. Offer acknowledgement when (the) caregiver performs home safety evaluation and modification'(Sadak et al., 2017; Study Finding).

\section{Interface with professionals}

Healthcare professionals contributed to self-management of long-term conditions by recognising when changes in cognition occurred (Bunn et al., 2017a) and supporting the family carer to in turn manage or support the care recipient (Sadak et al., 2017). Collaboration with General Practitioners, pharmacists, case managers and home care workers can support self-management, and management supported by a proxy (While et al., 2013). General Practitioners were described as the main support and pharmacists as important in medication management. However, family carers reported feeling healthcare professionals did not always alert them to symptoms to look for.

'Maybe his doctor could have instructed me better what to do to prevent these episodes, ask me if I know what to do or whom and when to call' (Sadak et al., 2017; Family Carer). 
The provision of symptom checklists, key information on medication and condition-specific education by healthcare professionals carers helped family carers to manage by proxy (Poland et al., 2014). One randomised controlled trial compared diabetic glucose control and complication rates between participants allocated to three different protocols for diabetes management of different intensities. Of relevance to this paper, the arm advocating less intensive control by health professionals, with personalised treatment plans and a focus on client and family-led management resulted in fewer diabetic complications.

'The personalized treatment plan is recommended by the moderate blood glucose control strategy. This strategy emphasizes on the control of blood glucose according to the actual conditions of patients, including the patients themselves and their families. This strategy recommends the physicians' intervention only in the cases of higher and wider fluctuation range' (Chen et al., 2017; Study Finding).

Improved blood glucose control in dementia was also associated with more physician attention, patient cooperation, and frequency of follow up (Chen et al., 2017).

Healthcare professionals were the primary source of information for medication management, especially during decision-making (Gillespie et al., 2015). In interviews with healthcare professionals and family carers of dementia, collaboration with professionals was facilitated when family carers felt more able to ask questions, and understand which symptoms to monitor and report (Sadak et al., 2017). However, a belief among patients that a good patient does not bother or question professional advice was a barrier to successful collaboration.

'I don't bother them, asking more questions about it, I just am a good patient, I just take it' (While et al., 2013; Person with Dementia).

One study using semi-structured interviews to explore the differences between the medication management experiences of people with dementia $(n=8)$ and carers $(n=9)$, found that health professionals were not considered to adequately explore an individual's values and beliefs underpinning their motivations and incentives to adhere to medication, or current attitudes to health, life and medication (While et al., 2013).

Values and beliefs of healthcare professionals also influenced the management of physical health care in people with dementia. In focus groups conducted with over fifty healthcare professionals, factors such as the clinician's previous experience and attitudes towards risk influenced access to care.

'I wouldn't refer someone who was uncooperative. I have had a patient who got up in the middle of a cataract operation and refused to have anything further done and lost the vision in his eye' (Bunn et al., 2017a; Healthcare Professional).

Ineffective communication and practices around confidentiality hindered collaboration between professionals. Included studies found continuity of care could overcome these barriers.

'... one of the big stumbling blocks we have is the fact that services or parts of different Trusts so the Mental Health Services sit within the H Partnership Trust so they don't use the same system as us so we can't share notes, the GPs use a different system again so it makes it very difficult to communicate to even find out what services people are under, you know, if that could be improved, if we could all be on the same system that would be good' (Bunn et al., 2017a; Healthcare Professional). 
In a case study of diabetes and dementia management using technologies, collaborative working could ensure effective use of technology, which enabled the management of long-term conditions through empowering individuals to self-care.

'There was concern that the patient would pull the pump site out or press the buttons on the pump. To avoid any concerns related to the patient wearing the insulin pump, a soft waist belt with a pocket was used to keep the insulin pump out of the patient's view. The safety lock was on the pump at all times to avoid accidental bolus' (Allen et al., 2017; Study Finding).

\section{Discussion}

We developed four overarching themes encompassing the enabling and inhibiting factors to effective self-management of long-term conditions in people with dementia. Most included studies investigated self-management of physical health care across long-term conditions, though a few focussed specifically on medication management, or the care of people with diabetes and dementia. Reduced cognition impeded adherence to medication, exercise and diet due to an impaired understanding of long-term conditions. Adherence was less affected if the long-term condition preceded memory loss. Behavioural and psychological symptoms of dementia were often associated with the person with dementia refusing help from carers and consequently non-adherence. This was further complicated when people with dementia were unable to report symptoms or pain. Healthcare professionals supported adherence by simplifying daily routines. Physical barriers such as difficulties opening bottles due to arthritis could be overcome through introducing dosette boxes, while cognitive barriers were helped by memory aids.

Included studies described a shift in responsibility for self-care as dementia progressed, from full autonomy through carer support, to carers undertaking self-care activities on behalf of the person with dementia. This process has been previously described in a systematic review of self-care concepts (Matarese et al., 2018). Included studies reported that safety concerns were of paramount importance to family carers and often precipitated the transition of responsibility for self-management. People living with dementia often experience a loss of independence during this transition. Carers acknowledged the dilemma of balancing good physical care when self-efficacy declines, and the importance of empowerment and respecting the wishes of the person living with dementia to be involved in their own care.

Models of self-care within the literature conceptualise it as a partnership between healthcare providers, family members and the individual themselves (Matarese et al., 2018). Healthcare professionals support the process of management by a proxy through providing condition-specific education, information on medication, and symptom checklists. Healthcare professionals must explore the values and beliefs of stakeholders, such as attitude to life, health and medication, to avoid a sense of reliance and overcome the belief that a good patient does not question professional advice. Collaborative working between professionals is required to improve communication between services.

Family carers are often critical in supporting adherence to treatments and in recognising and managing long-term condition specific complications. Without an available carer, people with dementia are vulnerable to disjointed healthcare. One case study described the positive benefits of high levels of supervision in assisted living facilities. Identifying and supporting a paid carer to take this role where a family carer is unavailable is likely to be key to the wellbeing of people living with dementia and long-term condition without regular family help.

This is the first systematic review to focus on self-care of long-term conditions in dementia. Most included studies were qualitative. This methodology is more likely to relate to the research question of 
this review, as strategies are more likely to be suggested using qualitative approaches (Alsaeed et al., 2016). This review conducted a systematic original search of relevant studies using pre-determined eligibility criteria without any limitation to residential status.

The generalisability of results are limited by the extent of study findings; most included studies reported on diabetes or general health and medication management. Generalisability of findings is also constrained by the inclusion of papers written in English only. The quantitative and mixed methodology studies included were rated as lower quality than qualitative studies. The guidelines for the Mixed Methods Appraisal Tool do not suggest excluding studies based on quality. However this has implications for the conclusions of this review due to the quality of included papers. Using a datadriven convergent synthesis enabled the inclusion of the result section of quantitative papers in the synthesis for this review. Despite this, the themes from this review are primarily based on the findings of qualitative papers due to their higher quality and richness of relevant data.

Previous reviews have focused on one long-term condition (Santos et al., 2018), excluded nursing home populations (Bunn et al., 2017b) or described the impact of cognitive impairment on long-term condition management rather than strategies to overcome this (Baird et al., 2017). Future research should seek to explore if there are differences in the enabling and inhibiting factors for different longterm conditions in dementia. The strategies suggested in qualitative studies can inform future intervention development. Most studies interviewed family members of people with dementia and focused on medication management. We found limited evidence of how other stakeholders can support self-management of long-term conditions in treatment wider than oral medication. Future research into how other stakeholders support long-term condition management in dementia is required, especially the role of paid carers who support people without a regular family carer. We did not include studies that explored the management of conditions in people with cognitive impairment without diagnosed dementia. These could inform future development of interventions to improve selfcare in people living with dementia. For example, trials of self-care interventions for people with diabetes and cognitive impairment could potentially be adapted to dementia populations in future research (Braun et al., 2004).

\section{Conclusions}

The findings of this review highlight the importance of collaboration between stakeholders in the management of long-term conditions in dementia. Personalised treatment plans should be rooted in an understanding of how the person's cognition may be influencing their self-care and adherence, including an exploration of values and beliefs. Healthcare professionals must value the carer role in long-term condition management, and support them by simplifying routines where possible, and providing condition-specific education as appropriate. Partnerships between stakeholders, including people living with dementia, their families, clinical and paid home carers are central to joined-up approaches to long-term condition management in dementia. Building explicit discussion of how these partnerships will work and guidance on strategies carers can use to support people to manage long-term conditions into care planning would be a rational strategy for improving long-term condition self-care in people living with dementia. 


\section{References}

Allen, N.A., Litchman, M.L., May, A.L., 2017. Using advanced diabetes technologies in patients with dementia in assisted living facilities: Case studies. Cogent Med. 4, 8-15. https://doi.org/10.1080/2331205x.2017.1411632

Alsaeed, D., Jamieson, E., Gul, M.O., Smith, F.J., 2016. Challenges to optimal medicines use in people living with dementia and their caregivers: A literature review. Int. J. Pharm. 512, 396404. https://doi.org/10.1016/j.ijpharm.2015.12.050

Aston, L., Hilton, A., Moutela, T., Shaw, R., Maidment, I., 2017. Exploring the evidence base for how people with dementia and their informal carers manage their medication in the community: A mixed studies review. BMC Geriatr. 17, 1-11. https://doi.org/10.1186/s12877-017-0638-6

Baird, C., Lovell, J., Johnson, M., Shiell, K., Ibrahim, J.E., 2017. The impact of cognitive impairment on self-management in chronic obstructive pulmonary disease: A systematic review. Respir. Med. 129, 130-139. https://doi.org/10.1016/j.rmed.2017.06.006

Barnett, K., Mercer, S.W., Norbury, M., Watt, G., Wyke, S., Guthrie, B., 2012. Epidemiology of multimorbidity and implications for health care, research, and medical education: A crosssectional study. Lancet 380, 37-43. https://doi.org/10.1016/S0140-6736(12)60240-2

Black, B.S., Johnston, D., Morrison, A., Rabins, P. V., Lyketsos, C.G., Samus, Q.M., 2012. Quality of life of community-residing persons with dementia based on self-rated and caregiver-rated measures. Qual. Life Res. 21, 1379-1389. https://doi.org/10.1007/s11136-011-0044-z

Braun, A., Muller, U.A., Muller, R., Leppert, K., Schiel, R., 2004. Structured treatment and teaching of patients with Type 2 diabetes mellitus and impaired cognitive function - The DICOF trial. Diabet. Med. 21, 999-1006. https://doi.org/10.1111/j.1464-5491.2004.01281.x

Brauner, D., 2009. Adherence to medication in patients with dementia: Problems and solutions. Geriatr. Aging 12, 259-263.

Brauner, D.J., Muir, J.C., Sachs, G.A., 2000. Treating nondementia illnesses in patients with dementia. JAMA 283, 3230-5.

Browne, J., Edwards, D.A., Rhodes, K.M., Brimicombe, D.J., Payne, R.A., 2017. Association of comorbidity and health service usage among patients with dementia in the UK: A populationbased study. BMJ Open 7, 1-8. https://doi.org/10.1136/bmjopen-2016-012546

Bunn, F., Burn, A.-M., Goodman, C., Robinson, L., Rait, G., Norton, S., Bennett, H., Poole, M., Schoeman, J., Brayne, C., 2016. Comorbidity and dementia: a mixed-method study on improving health care for people with dementia (CoDem). Heal. Serv. Deliv. Res. 4, 1-156. https://doi.org/10.3310/hsdr04080

Bunn, F., Burn, A.M., Robinson, L., Poole, M., Rait, G., Brayne, C., Schoeman, J., Norton, S., Goodman, C., 2017a. Healthcare organisation and delivery for people with dementia and comorbidity: A qualitative study exploring the views of patients, carers and professionals. BMJ Open 7, 1-9. https://doi.org/10.1136/bmjopen-2016-013067

Bunn, F., Goodman, C., Jones, P.R., Russell, B., Trivedi, D., Sinclair, A., Bayer, A., Rait, G., RycroftMalone, J., Burton, C., 2017b. Managing diabetes in people with dementia: A realist review. Health Technol. Assess. (Rockv). 21, 1-139. https://doi.org/10.3310/hta21750

Chen, Y., Wang, J., Wang, L.-J., Lin, H., Huang, P.-J., 2017. Effect of different blood glucose intervention plans on elderly people with type 2 diabetes mellitus combined with dementia. Eur. Rev. Med. Pharmacol. Sci. 21, 2702-2707.

Cooper, C., Lodwick, R., Walters, K., Raine, R., Manthorpe, J., Iliffe, S., Petersen, I., 2017. Inequalities in receipt of mental and physical healthcare in people with dementia in the UK. Age 
Currie, K., Rideout, A., Lindsay, G., Harkness, K., 2015. The Association Between Mild Cognitive Impairment and Self-care in Adults With Chronic Heart Failure. J. Cardiovasc. Nurs. 30, 382393. https://doi.org/10.1097/jen.0000000000000173

De Oliveira, F.F., Wajman, J.R., Bertolucci, P.H.F., 2014. Conhecimento dos cuidadores acerca do risco cerebrovascular de pacientes com síndrome demencial da doença de alzheimer em são paulo, Brasil. Rev. Psiquiatr. Clin. 41, 77-81. https://doi.org/10.1590/0101-60830000000015

Department of Health and Social Care, 2012. Long Term Conditions Compendium published.

Feil, D.G., Lukman, R., Simon, B., Walston, A., Vickrey, B., 2011. Impact of dementia on caring for patients' diabetes. Aging Ment. Heal. 15, 894-903. https://doi.org/10.1080/13607863.2011.569485

Gillespie, R.J., Harrison, L., Mullan, J., 2015. Medication management concerns of ethnic minority family caregivers of people living with dementia. Dementia 14, 47-62. https://doi.org/10.1177/1471301213488900

Guthrie, B., Payne, K., Alderson, P., McMurdo, M.E.T., Mercer, S.W., 2012. Adapting clinical guidelines to take account of multimorbidity. BMJ 345, 1-5. https://doi.org/10.1136/bmj.e6341

Hong, Q., Pluye, P., Fàbregues, S., Bartlett, G., Boardman, F., Cargo, M., Dagenais, P., Gagnon, M-P, Griffiths F, Nicolau B, O’Cathain A, Rousseau M-C, V.I., 2018. Mixed Methods Appraisal Tool (MMAT), version 2018.

Ibrahim, J.., Anderson., L.., Davis., M, C., MacPhail., A., Lovell., J., Winbolt., M., 2017. Chronic disease self-management support for persons with dementia, in a clinical setting. J. Multidiscip. Healthc. 10, 49-58.

Kingston, A., Robinson, L., Booth, H., Knapp, M., Jagger, C., 2018. Projections of multi-morbidity in the older population in England to 2035: estimates from the Population Ageing and Care Simulation (PACSim) model. Age Ageing 47, 374-380. https://doi.org/10.1093/ageing/afx201

Lim, R.H., Sharmeen, T., 2018. Medicines management issues in dementia and coping strategies used by people living with dementia and family carers: A systematic review. Int. J. Geriatr. Psychiatry 33, 1562-1581. https://doi.org/10.1002/gps.4985

Lorig, K.R., Holman, H.R., 2003. Self-management education: History, definition, outcomes, and mechanisms. Ann. Behav. Med. 26, 1-7. https://doi.org/10.1207/S15324796ABM2601_01

Marengoni, A., Angleman, S., Melis, R., Mangialasche, F., Karp, A., Garmen, A., Meinow, B., Fratiglioni, L., 2011. Aging with multimorbidity: A systematic review of the literature. Ageing Res. Rev. 10, 430-439. https://doi.org/10.1016/j.arr.2011.03.003

Matarese, M., Lommi, M., De Marinis, M.G., Riegel, B., 2018. A Systematic Review and Integration of Concept Analyses of Self-Care and Related Concepts. J. Nurs. Scholarsh. 50, 296-305. https://doi.org/10.1111/jnu.12385

Moher, D., Liberati, A., Tetzlaff, J., Altman, D.G., Group, T.P., 2009. Preferred Reporting Items for Systematic Reviews and Meta-Analyses: The PRISMA Statement. PLoS Med. 6, e1000097. https://doi.org/10.1371/journal.pmed.1000097

Pace, R., Pluye, P., Bartlett, G., Macaulay, A.C., Salsberg, J., Jagosh, J., Seller, R., 2012. Testing the reliability and efficiency of the pilot Mixed Methods Appraisal Tool (MMAT) for systematic mixed studies review. Int. J. Nurs. Stud. 49, 47-53.

https://doi.org/10.1016/j.ijnurstu.2011.07.002

Pluye, P., Nha Hong, Q., 2014. Combining the Power of Stories and the Power of Numbers: Mixed Methods Research and Mixed Studies Reviews. Ssrn. https://doi.org/10.1146/annurev- 
publhealth-032013-182440

Poblador-Plou, A., C.-L., J., M.-M., J., H.-S., A., S.-M., M., S., 2014. Comorbidity of dementia: A cross-sectional study of primary care older patients. BMC Psychiatry 14, 84. https://doi.org/http://dx.doi.org/10.1186/1471-244X-14-84

Poland, F., Mapes, S., Pinnock, H., Katona, C., Sorensen, S., Fox, C., Maidment, I.D., 2014. Perspectives of carers on medication management in dementia: Lessons from collaboratively developing a research proposal. BMC Res. Notes 7, 1-10. https://doi.org/10.1186/1756-0500-7463

Popay, J., Arai, L., Britten, N., 2006. Guidance on the conduct of narrative synthesis in systematic reviews: A product from the ESRC Methods Programme Information needs of adolescents with Adolescent Idiopathic Scoliosis: a multifaceted study View project The SENS project View project. https://doi.org/10.13140/2.1.1018.4643

Prince, M., Wimo, A., Guerchet, M., Ali, G.C., Wu, Y.T., Prina, M., 2015. World Alzheimer Report 2015. London, UK. Alzheimer's Dis. Int. 1-92. https://doi.org/10.1111/j.09637214.2004.00293.x

QSR International Pty, 2018. NVivo qualitative data analysis software.

Quinn, C., Toms, G., Anderson, D., Clare, L., 2016. A review of self-management interventions for people with dementia and mild cognitive impairment. J. Appl. Gerontol. 35, 1154-1188. https://doi.org/10.1177/0733464814566852

Rosen, M.I., Beauvais, J.E., Rigsby, M.O., Salahi, J.T., Ryan, C.E., Cramer, J.A., 2003. Neuropsychological correlates of suboptimal adherence to metformin. J. Behav. Med. 26, 34960 .

Sadak, T., Foster Zdon, S., Ishado, E., Zaslavsky, O., Borson, S., 2017. Potentially preventable hospitalizations in dementia: Family caregiver experiences. Int. Psychogeriatrics 29, 1201-1211. https://doi.org/10.1017/S1041610217000217

Sadak, T., Wright, J., Borson, S., 2018. Managing Your Loved One's Health: Development of a New Care Management Measure for Dementia Family Caregivers. J. Appl. Gerontol. 37, 620-643. https://doi.org/10.1177/0733464816657472

Santos, T., Lovell, J., Shiell, K., Johnson, M., Ibrahim, J.E., 2018. The impact of cognitive impairment in dementia on self-care domains in diabetes: A systematic search and narrative review. Diabetes. Metab. Res. Rev. 34, 1-16. https://doi.org/10.1002/dmrr.3013

Schubert, C.C., Boustani, M., Callahan, C.M., Perkins, A.J., Carney, C.P., Fox, C., Unverzagt, F., Hui, S., Hendrie, H.C., 2006. Comorbidity profile of dementia patients in primary care: Are they sicker? J. Am. Geriatr. Soc. 54, 104-109. https://doi.org/10.1111/j.1532-5415.2005.00543.x

Thomas, J., Harden, A., 2008. Methods for the thematic synthesis of qualitative research in systematic reviews. BMC Med. Res. Methodol. 8, 45. https://doi.org/10.1186/1471-2288-8-45

While, C., Duane, F., Beanland, C., Koch, S., 2013. Medication management: The perspectives of people with dementia and family carers. Dementia 12, 734-750. https://doi.org/10.1177/1471301212444056

Wong, G., Greenhalgh, T., Westhorp, G., Buckingham, J., Pawson, R., 2013. RAMESES publication standards: realist syntheses. BMC Med. 11, 21. https://doi.org/10.1186/1741-7015-11-21

Yarnall, A.J., Hayes, L., Hawthorne, G.C., Candlish, C.A., Aspray, T.J., 2012. Diabetes in care homes: Current care standards and residents' experience. Diabet. Med. 29, 132-135. https://doi.org/10.1111/j.1464-5491.2011.03393.x 
490 The following search was conducted on the $28^{\text {th }}$ of November 2019 using OVID to search Medline, 491 PsychINFO, Embase and Allied and Complementary Medicine.

\begin{tabular}{|c|c|c|}
\hline & MESH terms & Free text terms \\
\hline Management & $\begin{array}{l}\text { Self-Management } \\
\text { Self-Care } \\
\text { Patient Education as Topic } \\
\text { Health promotion } \\
\text { Disease management } \\
\text { Medication adherence } \\
\text { Patient Compliance } \\
\text { Healthy Diet } \\
\text { Exercise } \\
\text { Smoking cessation } \\
\text { Nebulizers and Vaporizers } \\
\text { Breathing exercises }\end{array}$ & $\begin{array}{l}\text { self manag* or Self-manag* or Self-car* or self- } \\
\text { care or self-monitor* or self-regulat* or drug } \\
\text { manag* or medication concordance or } \\
\text { prescription manag* or prescription concordance } \\
\text { or medicine manag* or adherence or long-term } \\
\text { medication or diet* advice or fluid intake/ or } \\
\text { fluid restriction or nutritional status or physical } \\
\text { activity or breathing control or peak flow or } \\
\text { health coaching or appointment* or manage*or } \\
\text { disease manage* or glucose }\end{array}$ \\
\hline \multicolumn{3}{|l|}{ AND } \\
\hline Dementia & $\begin{array}{l}\text { Dementia } \\
\text { Alzheimer's Disease }\end{array}$ & dementia* or alzheimer's* \\
\hline \multicolumn{3}{|l|}{ AND } \\
\hline $\begin{array}{l}\text { Physical } \\
\text { Health }\end{array}$ & $\begin{array}{l}\text { Health Status } \\
\text { Chronic Disease } \\
\text { Long-Term Care } \\
\text { Primary Health Care }\end{array}$ & $\begin{array}{l}\text { physical health or primary care or long-term } \\
\text { condition or long-term effects or long-term } \\
\text { condition or chronic condition or chronic disease } \\
\text { or chronic illness }\end{array}$ \\
\hline \multicolumn{3}{|r|}{ ( } \\
\hline Conditions & $\begin{array}{l}\text { Pulmonary Disease, Chronic } \\
\text { Obstructive } \\
\text { Osteoarthritis } \\
\text { Cardiovascular disease } \\
\text { Heart Failure } \\
\text { Coronary disease } \\
\text { Diabetes Mellitus, Type 1, Type 2 }\end{array}$ & $\begin{array}{l}\text { asthma or bronchitis or inhalation or chronic } \\
\text { pain or arthritis or Heart disease or heart failure } \\
\text { or } \\
\text { Rheumatology or diabetes or diabetes mellitus }\end{array}$ \\
\hline
\end{tabular}


Table 2: Characteristics of included studies

\begin{tabular}{|c|c|c|c|c|}
\hline $\begin{array}{l}\text { Author } \\
\text { \& Location }\end{array}$ & Study Aim & Sample & $\begin{array}{l}\text { Study type, } \\
\text { Data analysis }\end{array}$ & Main Finding \\
\hline $\begin{array}{l}\text { (Allen et al., } \\
\text { 2017), USA }\end{array}$ & $\begin{array}{l}\text { Describe technology use } \\
\text { for diabetes and dementia. }\end{array}$ & $\begin{array}{l}2 \text { people with } \\
\text { dementia \& diabetes. }\end{array}$ & Case study. & $\begin{array}{l}\text { Wearable diabetes technologies reduced glucose variability, } \\
\text { hypoglycaemia \& improving wellbeing and care. }\end{array}$ \\
\hline $\begin{array}{l}\text { (Brauner et al., } \\
2000), \text { USA }\end{array}$ & $\begin{array}{l}\text { Understand how dementia } \\
\text { affects treatment for non- } \\
\text { dementia illnesses. }\end{array}$ & $\begin{array}{l}1 \text { person with } \\
\text { dementia \& } \\
\text { osteoporosis. }\end{array}$ & Case study. & $\begin{array}{l}\text { Decision-making capacity, altered benefits and burdens, ability to adhere } \\
\text { and report adverse events and availability of caregivers important in } \\
\text { treating non-dementia illnesses. }\end{array}$ \\
\hline $\begin{array}{l}\text { (Gillespie et } \\
\text { al., 2015), } \\
\text { Australia }\end{array}$ & $\begin{array}{l}\text { Medication management } \\
\text { experiences of ethnic } \\
\text { minority family carers of } \\
\text { dementia. }\end{array}$ & $\begin{array}{l}29 \text { family carers for } \\
\text { dementia and diabetes, } \\
\text { arthritis, hypertension, } \\
\text { osteoporosis. }\end{array}$ & $\begin{array}{l}\text { Focus group and } \\
\text { semi-structured } \\
\text { interviews, } \\
\text { thematic } \\
\text { analysis. }\end{array}$ & $\begin{array}{l}\text { Themes: 1) Medication management is stressful for family carers; 2) } \\
\text { Medication management may be a point of conflict; 3) Family support is } \\
\text { critical; 4) family carers want external information and support. }\end{array}$ \\
\hline $\begin{array}{l}\text { (Poland et al., } \\
\text { 2014), UK }\end{array}$ & $\begin{array}{l}\text { Views of medication } \\
\text { management in dementia } \\
\text { through patient and public } \\
\text { involvement. }\end{array}$ & $\begin{array}{l}9 \text { carers from research } \\
\text { network for people } \\
\text { with pain, } \\
\text { hypertension, diabetes } \\
\text { osteoporosis. }\end{array}$ & $\begin{array}{l}\text { Workshop, } \\
\text { focus group, } \\
\text { thematic and } \\
\text { narrative } \\
\text { analysis. }\end{array}$ & $\begin{array}{l}\text { Themes: (1) Medication use and administration practicalities; (2) } \\
\text { Communication barriers and facilitators; (3) Bearing and sharing } \\
\text { responsibility; (4) Weighing up medication risk and benefits. }\end{array}$ \\
\hline $\begin{array}{l}\text { (Sadak et al., } \\
\text { 2018), USA }\end{array}$ & $\begin{array}{l}\text { Develop measure to } \\
\text { monitor family carer } \\
\text { management of dementia } \\
\text { healthcare. }\end{array}$ & $\begin{array}{l}16 \text { healthcare } \\
\text { professionals, } 35 \\
\text { family carers of } \\
\text { dementia focus on } \\
\text { general health. }\end{array}$ & $\begin{array}{l}\text { Focus groups, } \\
\text { stepwise } \\
\text { attribute } \\
\text { manner. }\end{array}$ & $\begin{array}{l}\text { Themes: (1) Dementia influences health/Family carers responsible for } \\
\text { health needs; (2) People with dementia and family carers are a unit of } \\
\text { care/self-care not prioritised in family carers; (3) Activated family carers } \\
\text { better/Family carers defer the expert role to clinicians; (4) Good self- } \\
\text { care is necessary/Professionals disregard their views and opinions; (5) } \\
\text { Family carers uncomfortable asking for help. }\end{array}$ \\
\hline $\begin{array}{l}\text { (While et al., } \\
\text { 2013), } \\
\text { Australia }\end{array}$ & $\begin{array}{l}\text { Differences in medication } \\
\text { management for people } \\
\text { with dementia and family } \\
\text { carers. }\end{array}$ & $\begin{array}{l}8 \text { people with } \\
\text { dementia and } 9 \text { family } \\
\text { carers administering } \\
\text { medication at home, } \\
\text { discusses stroke. } \\
\end{array}$ & $\begin{array}{l}\text { Semi-structured } \\
\text { interviews, } \\
\text { grounded } \\
\text { theory. }\end{array}$ & $\begin{array}{l}\text { Themes: (1) Self-management; (2) Something changes; (3) Family carer } \\
\text { advocacy; (4) The medication team. }\end{array}$ \\
\hline
\end{tabular}




\begin{tabular}{|c|c|c|c|c|}
\hline $\begin{array}{l}\text { (Bunn et al., } \\
\text { 2017a), UK }\end{array}$ & $\begin{array}{l}\text { Impact of dementia on } \\
\text { access to non-dementia } \\
\text { services. }\end{array}$ & $\begin{array}{l}28 \text { people with } \\
\text { dementia, } 33 \text { family } \\
\text { carers and } 56 \\
\text { professionals, people } \\
\text { with diabetes, stroke, } \\
\text { visual impairment. }\end{array}$ & $\begin{array}{l}\text { Semi-structured } \\
\text { interviews and } \\
\text { focus groups, } \\
\text { thematic } \\
\text { analysis. }\end{array}$ & $\begin{array}{l}\text { Themes: (1) Family carers facilitate access to care and continuity of } \\
\text { care; (2) Dementia severity \& management; (3) Communication and } \\
\text { collaboration. }\end{array}$ \\
\hline $\begin{array}{l}\text { (Feil et al., } \\
\text { 2011), USA }\end{array}$ & $\begin{array}{l}\text { Family carer challenges } \\
\text { experience of managing } \\
\text { diabetes in people with } \\
\text { dementia. }\end{array}$ & $\begin{array}{l}21 \text { family carers of } \\
\text { people with dementia } \\
\text { and diabetes. }\end{array}$ & $\begin{array}{l}\text { Focus group, } \\
\text { grounded } \\
\text { theory. }\end{array}$ & $\begin{array}{l}\text { Themes: (1) Memory loss led to family carer intervention; (2) } \\
\text { Behavioural and psychological symptoms disrupted diabetes care } \\
\text { routine; (3) Diabetes and dementia highly burdensome, and more } \\
\text { support required. }\end{array}$ \\
\hline $\begin{array}{l}\text { (Sadak et al., } \\
\text { 2017), USA }\end{array}$ & $\begin{array}{l}\text { Family carer experience } \\
\text { of dementia health crises. }\end{array}$ & $\begin{array}{l}20 \text { family carer of } \\
\text { people hospitalised for } \\
\text { heart failure, } \\
\text { hypertension or } \\
\text { COPD. }\end{array}$ & $\begin{array}{l}\text { Semi-structured } \\
\text { interviews. }\end{array}$ & $\begin{array}{l}\text { Themes: (1) Uncertain act on the change; (2) Unable to provide } \\
\text { necessary care; (3) Family carer experiences a personal crisis } \\
\text { (4) Mitigating factors may prevent caregiver crises. }\end{array}$ \\
\hline $\begin{array}{l}\text { (Yarnall et al., } \\
\text { 2012), UK }\end{array}$ & $\begin{array}{l}\text { Assess diabetes care in } \\
\text { UK care homes and } \\
\text { including resident views. }\end{array}$ & $\begin{array}{l}31 \text { people with } \\
\text { dementia living in } 7 \\
\text { care homes, } 5 \\
\text { managers and } 7 \text { staff. }\end{array}$ & $\begin{array}{l}\text { Questionnaire } \\
\text { and qualitative } \\
\text { semi-structured } \\
\text { interviews. }\end{array}$ & $\begin{array}{l}63 \% \text { of people with dementia had glucose monitored unnecessarily. One } \\
\text { staff with diabetes training. } 90 \% \text { saw a chiropodist and }>80 \% \text { had an eye } \\
\text { screening. Themes: 1) diabetes understanding/complications; } 2 \text { ) } \\
\text { information from professionals. }\end{array}$ \\
\hline $\begin{array}{l}\text { (Chen et al., } \\
\text { 2017), China }\end{array}$ & $\begin{array}{l}\text { To analyse the effects of } \\
\text { intensive and mitigation } \\
\text { blood glucose control. }\end{array}$ & $\begin{array}{l}90 \text { people with } \\
\text { dementia and diabetes } \\
\text { randomly allocated to } \\
\text { control (diet/exercise), } \\
\text { insulin/medication or } \\
\text { personalised treatment. }\end{array}$ & $\begin{array}{l}\text { Clinical } \\
\text { observation, } \\
\text { quantitative. }\end{array}$ & $\begin{array}{l}\text { Moderate control of glucose and proper increase of target value benefit } \\
\text { diabetes management in people with dementia. Personalised treatment } \\
\text { plan recommended. }\end{array}$ \\
\hline $\begin{array}{l}\text { (De Oliveira et } \\
\text { al., 2014), } \\
\text { Brazil }\end{array}$ & $\begin{array}{l}\text { How awareness of } \\
\text { cerebrovascular risks } \\
\text { impact adherence. }\end{array}$ & $\begin{array}{l}\text { Questionnaire for } 217 \\
\text { family carer of } \\
\text { dementia outpatients } \\
650 \text { with diabetes and } \\
\text { hypertension. }\end{array}$ & Questionnaires. & $\begin{array}{l}\text { Family carer awareness of the need to control cerebrovascular risk has } \\
\text { positive impacts for people with dementia. }\end{array}$ \\
\hline
\end{tabular}


679 Table 3: Quality evaluation of included studies using the mixed methods appraisal tool (2018)*

\begin{tabular}{|c|c|c|c|c|c|c|c|c|c|c|c|c|c|c|}
\hline 680 & 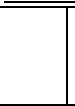 & 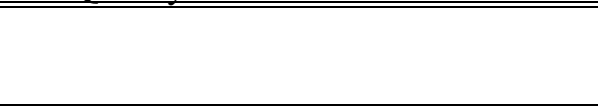 & $\begin{array}{l}\text { (Allen et } \\
\text { al., 2017) }\end{array}$ & \begin{tabular}{|l} 
(Brauner \\
et al., \\
$2000)$ \\
\end{tabular} & $\begin{array}{l}\text { (Bunn et } \\
\text { al., } \\
\text { 2017a) } \\
\end{array}$ & $\begin{array}{l}\text { (Chen } \\
\text { et al., } \\
\text { 2017) }\end{array}$ & $\begin{array}{l}\text { De } \\
\text { Oliveira et } \\
\text { al., 2014) }\end{array}$ & $\begin{array}{l}\text { (Feil et al., } \\
2011)\end{array}$ & $\begin{array}{l}\text { (Gillespie } \\
\text { et al., } \\
2015 \text { ) }\end{array}$ & $\begin{array}{l}\text { (Poland } \\
\text { et al., } \\
2014)\end{array}$ & $\begin{array}{l}\text { (Sadak et al., } \\
\text { 2017) }\end{array}$ & $\begin{array}{l}\text { (Sadak et } \\
\text { al., 2018) }\end{array}$ & $\begin{array}{l}\text { (While et } \\
\text { al., 2013) }\end{array}$ & $\begin{array}{l}\text { (Yarnall } \\
\text { et al., } \\
2012)\end{array}$ \\
\hline 681 & \multirow{5}{*}{ 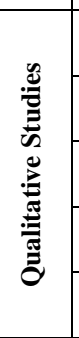 } & $\begin{array}{l}\text { 1.1. Is the qualitative approach appropriate to } \\
\text { answer the research question? }\end{array}$ & No & Yes & Yes & & & Yes & Yes & Yes & Yes & Yes & Yes & \\
\hline 682 & & $\begin{array}{l}\text { 1.2. Are the qualitative data collection methods } \\
\text { adequate to address the research question? }\end{array}$ & No & Can't tell & Yes & & & Yes & Yes & Yes & Yes & Yes & Yes & \\
\hline 683 & & $\begin{array}{l}\text { 1.3. Are the findings adequately derived from the } \\
\text { data? }\end{array}$ & Yes & Yes & Yes & & & Yes & Yes & Yes & Yes & Yes & Yes & \\
\hline 684 & & $\begin{array}{l}\text { 1.4. Is the interpretation of results sufficiently } \\
\text { substantiated? }\end{array}$ & Yes & No & Yes & & & Yes & Yes & Yes & No & No & Yes & \\
\hline 685 & & $\begin{array}{l}\text { 1.5. Is there coherence between qualitative data } \\
\text { sources, collection, analysis and interpretation? }\end{array}$ & Can't tell & Yes & Yes & & & Yes & Yes & Yes & Yes & Can't tell & Yes & \\
\hline 686 & \multirow{5}{*}{ 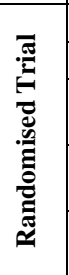 } & 2.1. Is randomization appropriately performed? & & & & Yes & & & & & & & & \\
\hline 687 & & 2.2. Are the groups comparable at baseline? & & & & Yes & & & & & & & & \\
\hline 688 & & 2.3. Are there complete outcome data? & & & & $\begin{array}{l}\text { Can't } \\
\text { tell }\end{array}$ & & & & & & & & \\
\hline 689 & & $\begin{array}{l}\text { 2.4. Are outcome assessors blinded to the } \\
\text { intervention? }\end{array}$ & & & & $\begin{array}{l}\text { Can't } \\
\text { tell }\end{array}$ & & & & & & & & \\
\hline 690 & & $\begin{array}{l}2.5 \text { Did the participants adhere to the assigned } \\
\text { intervention? }\end{array}$ & & & & Yes & & & & & & & & \\
\hline 691 & \multirow{5}{*}{ 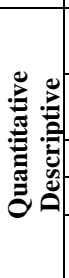 } & $\begin{array}{l}\text { 4.1. Is the sampling strategy relevant to address the } \\
\text { research question? }\end{array}$ & & & & & Yes & & & & & & & \\
\hline 692 & & $\begin{array}{l}\text { 4.2. Is the sample representative of the target } \\
\text { population? }\end{array}$ & & & & & Yes & & & & & & & \\
\hline 693 & & 4.3. Are the measurements appropriate? & & & & & Can’t tell & & & & & & & \\
\hline 694 & & 4.4. Is the risk of nonresponse bias low? & & & & & Yes & & & & & & & \\
\hline 695 & & $\begin{array}{l}\text { 4.5. Is the statistical analysis appropriate to answer } \\
\text { the research question? }\end{array}$ & & & & & No & & & & & & & \\
\hline 696 & \multirow{5}{*}{ 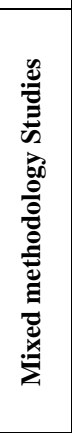 } & $\begin{array}{l}\text { 5.1. Is there an adequate rationale for using a mixed } \\
\text { methods design? }\end{array}$ & & & & & & & & & & & & Yes \\
\hline 697 & & $\begin{array}{l}\text { 5.2. Are the different components of the study } \\
\text { effectively integrated? }\end{array}$ & & & & & & & & & & & & No \\
\hline 698 & & $\begin{array}{l}\text { 5.3. Are the outputs of the integration of qualitative } \\
\text { and quantitative components adequately } \\
\text { interpreted? }\end{array}$ & & & & & & & & & & & & No \\
\hline 699 & & $\begin{array}{l}\text { 5.4. Are divergences and inconsistencies between } \\
\text { quantitative and qualitative results adequately } \\
\text { addressed? }\end{array}$ & & & & & & & & & & & & No \\
\hline 700 & & $\begin{array}{l}\text { 5.5. Do the different components of the study } \\
\text { adhere to the quality criteria of each tradition of the } \\
\text { methods involved? }\end{array}$ & & & & & & & & & & & & No \\
\hline
\end{tabular}

701 *The third category of studies included in the Mixed Method Appraisal Tool are quantitative non-randomised studies. As no such study has been included in our review, this category has been omitted from the table 
